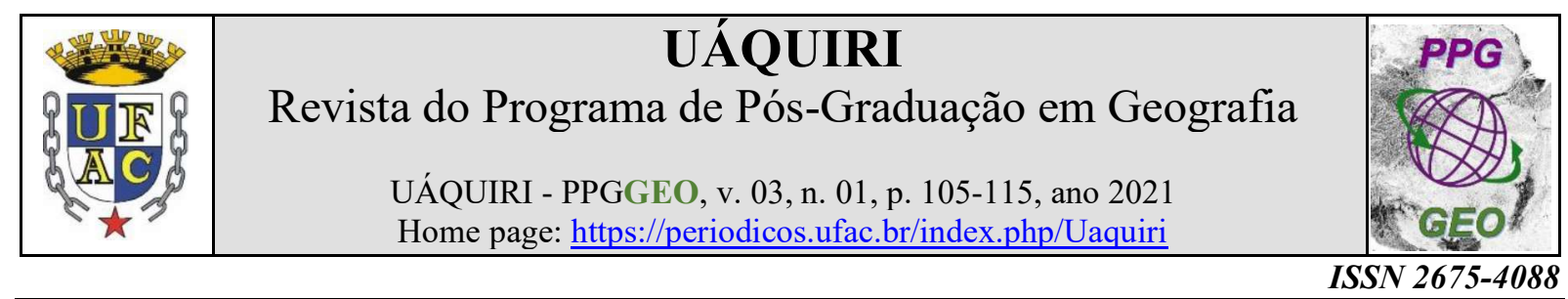

\title{
(RELATOS DE EXPERIENCIAS) \\ PROJETO AVANÇAR: PERSPECTIVA SOCIAL DE FORMAÇÃO \\ PROFISSIONAL POPULAR NO TERRITÓRIO DO MONTE CRISTO EM FLORIANÓPOLIS/SC
}

\author{
Msc. Rafael da Silva Cezar ${ }^{1 *}$, Ldo. Maria Marlene da Silva ${ }^{2}$ \\ ORCID: https://orcid.org/0000-0002-5725-4808, https://orcid.org/0000-0001-9008-8867
}
${ }^{1}$ Educador social no Centro de Educação Popular, Licenciado em Ciências biológicas, licenciando em Educação do Campo, Especialista em neuropsicopedagogia, Mestre em biologia celular e molecular aplicado à saúde e
Mestrando em educação científica e tecnológica;*
${ }^{2}$ Coordenadora geral do Centro de Educação Popular, Licenciada em pedagogia
*rafscezars@gmail.com
Aprovado como destaque no I Simpósio Nacional de Metodologias Ativas na Educação Profissional e Tecnológica (I SinmaEPT).
Publicado em: 30/07/2021
DOI: https://doi.org/10.47418/uaquiri.vol3.n1.2021.5137

\begin{abstract}
RESUMO
A educação profissional é aquela voltada para o mundo do trabalho e tem grande peso quanto a questão de projeto de vida de um sujeito, pensado dessa forma o CEDEP desenvolve o projeto avançar que visa trazer formação de forma popular para o bairro Monte Cristo na periferia de Santa Catarina, através dessas iniciativas auxiliamos na entrada do mercado de trabalho e na autonomia dos educandos participantes do projeto, auxiliando eles desde a confecção de documentos necessários, formação, indicação e fomento ao empreendedorismo, contando hoje com mais de 110 matriculados semestralmente.
\end{abstract}

Palavras-chave: Profissionalização; Educação Popular; Projeto de vida; Monte Cristo;

\section{AVANÇAR PROJECT: SOCIAL PERSPECTIVE OF POPULAR VOCATIONAL TRAINING IN THE TERRITORY OF MONTE CRISTO IN FLORIANÓPOLIS /SC}

\begin{abstract}
Professional education is one geared towards the world of work and has great weight in terms of the subject's life project, thought in this way CEDEP develops the project to advance, which aims to bring popular training to the Monte Cristo neighborhood on the outskirts of Santa Catarina, through these initiatives we assist in the entry of the labor market and in the autonomy of the students participating in the project, assisting them since the making of necessary documents, training, indication and promotion of entrepreneurship, counting today with more than 110 enrolled every six months
\end{abstract}

Keywords: Professionalization; Popular Education; Life project; Monte Cristo. 


\section{PROYECTO AVANÇAR: PERSPECTIVA SOCIAL DE LA FORMACIÓN PROFESIONAL POPULAR EN EL TERRITORIO DE MONTE CRISTO EN FLORIANÓPOLIS / SC}

\section{RESUMEN}

La educación profesional es aquella orientada al mundo laboral y tiene un gran peso en cuanto al proyecto de vida del sujeto, pensado de esta manera CEDEP desarrolla el proyecto para avanzar, que tiene como objetivo acercar la formación popular al barrio Monte Cristo en Santa Catarina, a través de estos iniciativas asistimos en la entrada al mercado laboral y en la autonomía de los estudiantes que participan en el proyecto, ayudándoles desde la preparación de los documentos necesarios, formación, indicación y promoción del emprendimiento, con más de 110 matriculados cada seis meses.

Palabras clave: Profesionalización; Educación Popular; Proyecto de vida; Monte Cristo;

\section{INTRODUÇÃO}

A Educação Profissional é aquela que se volta para o mundo do trabalho, para o aprendizado de uma profissão, de um ofício especializado, historicamente esse modelo educacional vem associado aos modelos de concepção econômica vigentes na região, estado ou mesmo na esfera federal, buscando especializar a função laboral às necessidades do mercado. Com isso este modelo educacional recebe grande influência política como também do setor privado representado pelos empresários no sentido de criar e manter cursos que, de alguma forma, possam suprir postos estratégicos para o desenvolvimento do país e da economia. (Figueiredo, 2017)

Segundo Moraes (2019), há uma grande carência de traba-lhadores qualificados, mesmo havendo certo investimento na forma-ção de profissionais pela modalidade de educação profissional e tecnológica, normalmente essas formações se concentram nos centros urbanos de grandes cidades e capitais, deixando assim grande parte da população periférica e marginalizada com grandes dificuldades de acesso a essas formações, seja pela locomoção, não reconhecimento do espaço como pertencente a si ou pela dificuldade de entrelaçar sua jornada profissional com o tempo investido para formação profissional, acabam por deixar de fora do processo de formação a população que mais teria interesse em ocupar estas vagas de trabalho com características mais operacionais e de atuação laboral.

Com isso fica evidente como discutem Moraes (2017) e Turmena (2017) que como estratégia para o desenvolvi-mento local, regional tanto como o nacional e o fortalecimento no processo de inserção cidadã de milhares de brasileiros está intimamente ligado à formação profissional.

A cidade de Florianópolis se destaca no cenário nacional pelo seu alto Índice de Desenvolvimento Humano (IDHM), ocupando o $3^{\circ}$ lugar entre os municípios brasileiros, com 
0,847. A dimensão que mais contribui para o IDHM do município é longevidade, com índice de 0,873, seguida de Renda, com índice de 0,870, e de Educação, com índice de 0,800.

O bairro Monte Cristo está localizado na parte continental de Florianópolis e, a partir do seu histórico de ocupações e acolhimento de famílias migrantes, foi constituindo-se de várias comunidades, como Chico Mendes, Novo Horizonte, Santa Terezinha I e II e Nova Esperança. Em 2010, os números revelam que residiam 6.024 pessoas no bairro, sendo uma maior proporção de mulheres $-52,54 \%$. A taxa de crescimento da população no bairro foi de $0,08 \%$ (Atlas Do Desenvolvimento Humano no Brasil, 2013).

Apesar do IDHM de Florianópolis ser um dos maiores do Brasil, os dados revelam que 1 em cada 7 crianças ou adolescentes estão vulneráveis à pobreza. Estima-se que a renda de $77 \%$ dos domicílios do bairro é de até 2 salários-mínimos. Em números, a renda média per capita dos moradores do Monte Cristo, em 2010, era de $\mathrm{R} \$ 929,08$, contrastando com a renda média de Florianópolis de R\$1.798,12 (Atlas Do Desenvolvimento Humano No Brasil, 2013).

Além disso, o índice GINI aponta para poucas melhorias na distribuição de renda de Florianópolis ao longo dos últimos anos. Em 2010, foram identificados 4.515 crianças e adolescentes trabalhando, sendo que a maioria (47\%) eram adolescentes entre 14 e 17 anos atuando na informalidade e sem nenhum direito trabalhista garantido.

Ainda cabe registrar como característica fundamental para vulnerabilidade da região a presença marcante do narcotráfico e, a partir dele, a absorção e aliciamento de crianças, adolescentes e jovens pelo crime organizado. Segundo estudos de Casseletti (2005), Mello Júnior (2004) e a partir de dados da Polícia Militar de Florianópolis sobre incidentes criminais atendidos em hospitais públicos, o Monte Cristo lidera o ranking de criminalidade e tráfico de drogas da cidade. Dentro de comunidades periféricas, a inserção dos adolescentes e jovens em espaços de criminalidade tem sido perpetuada e naturalizada, gerando um ciclo geracional, no qual a relação com o narcotráfico se mostra como alternativa possível para famílias da região, como discute Fefferman (2018).

A partir dessa necessidade do território surgiu o Centro de Educação Popular (CEDEP), uma Organização da Sociedade Civil (OSC) que há mais de 30 anos atua no bairro através de projetos de educação popular. Atualmente desenvolve suas ações a partir de 5 projetos e atende diariamente 450 crianças, adolescentes, jovens e adultos. Dentre esses projetos, possui o projeto Avançar tem como objetivo desenvolvimento laboral de adolescentes, jovens e adultos em prol da construção de projetos de vida a partir de cursos populares com parceiros nas diferentes áreas do conhecimento, entendendo como parte fundamental no processo de desenvolvimento de 
autonomia em suas escolhas, potencializando a formação cidadã. Atende pessoas em situação de vulnerabilidade social que possuam mais do que 14 anos a partir das necessidades apresentadas, especialmente ex-educandos que passaram pelo programa jovem aprendiz ou outros projetos do CEDEP e estão desempregados e pessoas da comunidade que estejam em busca inserção laboral.

O Objetivo deste trabalho é trazer e apresentar nossas metodologias de trabalho, a fim da disseminação das práticas populares nas regiões da periferia que atuam diretamente com formação profissional e laboral.

\section{METODOLOGIA.}

Dentro de sua metodologia o projeto Avançar realiza diversas ações, dentre elas temos:

- Atendimento individualizado para orientação e produção de documentos necessários para criação de vínculos empregatícios:

Uma realidade que permeia as periferias é a falta de acesso aos aparelhos públicos ou mesmo a falta de informação e orientação para manutenção de documentações básicas, como carteiras de identidade, carteira de trabalho, cadastro de pessoa física entre outros. Com isso aumentando a dificuldade do encontro de empregos formais e também acesso a qualquer iniciativa pública, a partir dessa necessidade o projeto Avançar já realiza o mapeamento dos adolescentes de 13 a 14 anos presentes na instituição e realiza o direcionamento junto aos responsáveis para marcação e produção de tais documentos como também realiza duas vezes por semana atendimento a comunidade para orientação e direcionamento de quem precise de auxílio para essas questões, facilitando assim o acesso a processos empregatícios

\section{- Cursos sazonais de formação profissional:}

Dentre um dos objetivos do projeto avançar é a proposta de cursos de livre duração voltados para formação profissional e laboral, com isso a instituição firma parceria com diversos órgãos responsáveis por tais ações e propõem que elas sejam realizadas dentro do espaço da instituição, com isso o curso toma outro formato mais próximo a comunidade e sua realidade.

Hoje já temos vínculo com diversas instituições, como Serviço Brasileiro de Apoio às Micro e Pequenas Empresas, Serviço Nacional de Aprendizagem Comercial, Google, Facebook, Junior Achievement, Banco Santander, que atuam de forma frequente com a produção de cursos, mas também existem parceiros pontuais que normalmente atuam em cursos 
mais específicos e rápidos, como cursos de Design de sobrancelhas, Barbearia, Cerâmica entre outros que tem um foco maior na produção do trabalho autônomo.

A oferta de cursos varia conforme educador, instituição parceira e sua grade de conteúdo, são promovidos conforme a necessidade de demanda do território e educandos, tendo seu planejamento e oferta em caráter semestral. Dentre os temas mais contemplados pelos cursos propostos estão os de serviços e aperfeiçoamento empresarial, tecnologias de informação, atendimento ao público, incentivo ao empreendedorismo e orientação vocacional.

\section{- Projetos de Empreendedorismo e Incubação de empresas:}

O Projeto avançar possui hoje uma parceria com o Cocreation Lab, ele atua como um laboratório de coworking voltado à pré-incubação de ideias e projetos de empresas do setor de economia criativa, anteriormente a esta ação já tinha diversos polos dentro da cidade de Florianópolis e região buscando trazer ideias criativas para papéis mais funcionais e otimizados no mercado, porém não havia ainda se aventurado a uma realidade de comunidades para adequar sua metodologia, porém como nos traz Savi (2019) tendo dentro de seus processos de oferecer um ambiente de trabalho colaborativo e o suporte decisivo na consolidação de ideias empreendedoras acaba por caracterizar iniciativas importantes e com grande potencial de transformação para estes territórios periféricos.

Este processo de pré-incubação se expressa por meio de mentorias, palestras, encontros, coletivos, para que empresas de pequeno e médio porte entrem no mercado mais preparadas para enfrentá-lo e modificá-lo e diante disso tudo também entendendo seu papel social.

- Preparação para processos seletivos e parceria com empresas para direcionamento:

Além de atuar diretamente na formação profissional de jovens e adultos o projeto avançar também realiza parceria com diversas empresas e OSC's específicas de direcionamento a processos de estágio e aprendizagem, com isso podemos ao final do processo de formação realizar a preparação dos jovens para processos seletivos, seja produzindo e auxiliando na proposta de currículos, preparação para entrevistas, indicação de jovens para vagas que contemplem seu perfil. Quando o indicado é selecionado para a vaga segue recebendo suporte durante todo processo empregatício e o acompanhando durante este período para que a efetivação se torne uma realidade, auxiliando também em formações necessárias para alavancar sua prática ou carreira. 


\section{RESULTADOS E DISCUSSÃO}

$\mathrm{O}$ atendimento individualizado para produção de documentação é um serviço muito frequente, hoje a comunidade periférica encontra grandes dificuldades, seja pela questão de locomoção interna no município ou tanto pela questão de acesso a ferramentas digitais, para produção e obtenção de documentos básicos como a carteira de identidade e a carteira de trabalho, serviços esses hoje que tem a necessidade de serem marcados ou realizados via internet, questão discutida por Ferreira (2018). O projeto avançar atende uma média de 04 pessoas semanalmente para orientação da carteira de identidade e uma média mensal de 03 pessoas para produção da carteira de trabalho. No mês de novembro realiza o contato direto com todos os educandos com idade de 14 anos do projeto para produção da documentação, que normalmente é uma média de 25 educandos que já estão em processo de formação final do atendimento do CEDEP.

Figura 1 e 2: Cadastro dos alunos do CEDEP para retirada da primeira carteira de documentações;
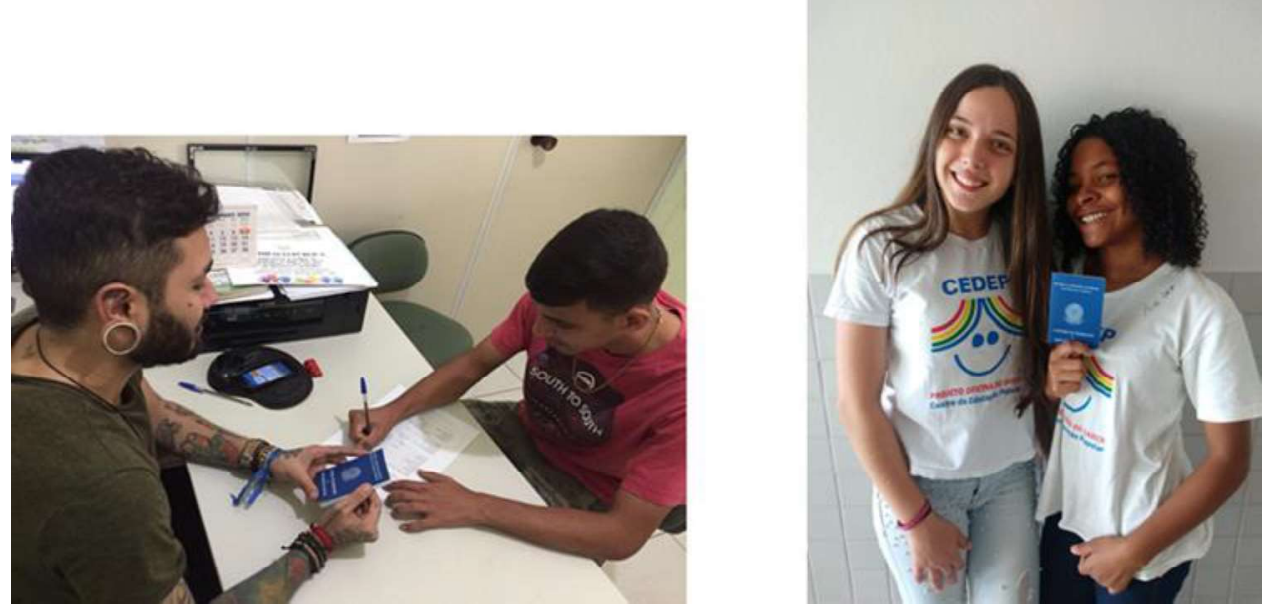

Quando entramos na esfera de cursos profissionalizantes conseguimos contar com um fluxo semestral de uma média de 110 matriculados, a faixa etária varia conforme proposta dos cursos empregados, sempre buscamos contemplar diferentes públicos durante o semestre, tendo ao mínimo um tempo de 05 cursos semestrais, sendo 03 com foco na entrada do mercado de trabalho, 01 com foco laboral e prática e 01 de confecção própria do CEDEP junto ao projeto Avançar para permitir uma discussão mais crítica quanto ao mercado de trabalho, todos os finalizastes do curso recebem acompanhamento e direcionamento para futuras vagas de trabalho, bem como passam a integrar no banco de dados de educandos para serem avisados de novas oportunidades, importante salientar que mesmo no momento de Pandemia do COVID- 
19 as ações de formação se mantiveram ativas, mesmo em modo online ou com distanciamento necessário.

Figura 3,4,5,6 e 7: Aulas ministradas e alunos do curso CADT (Curso Avançado direcionado ao trabalho).
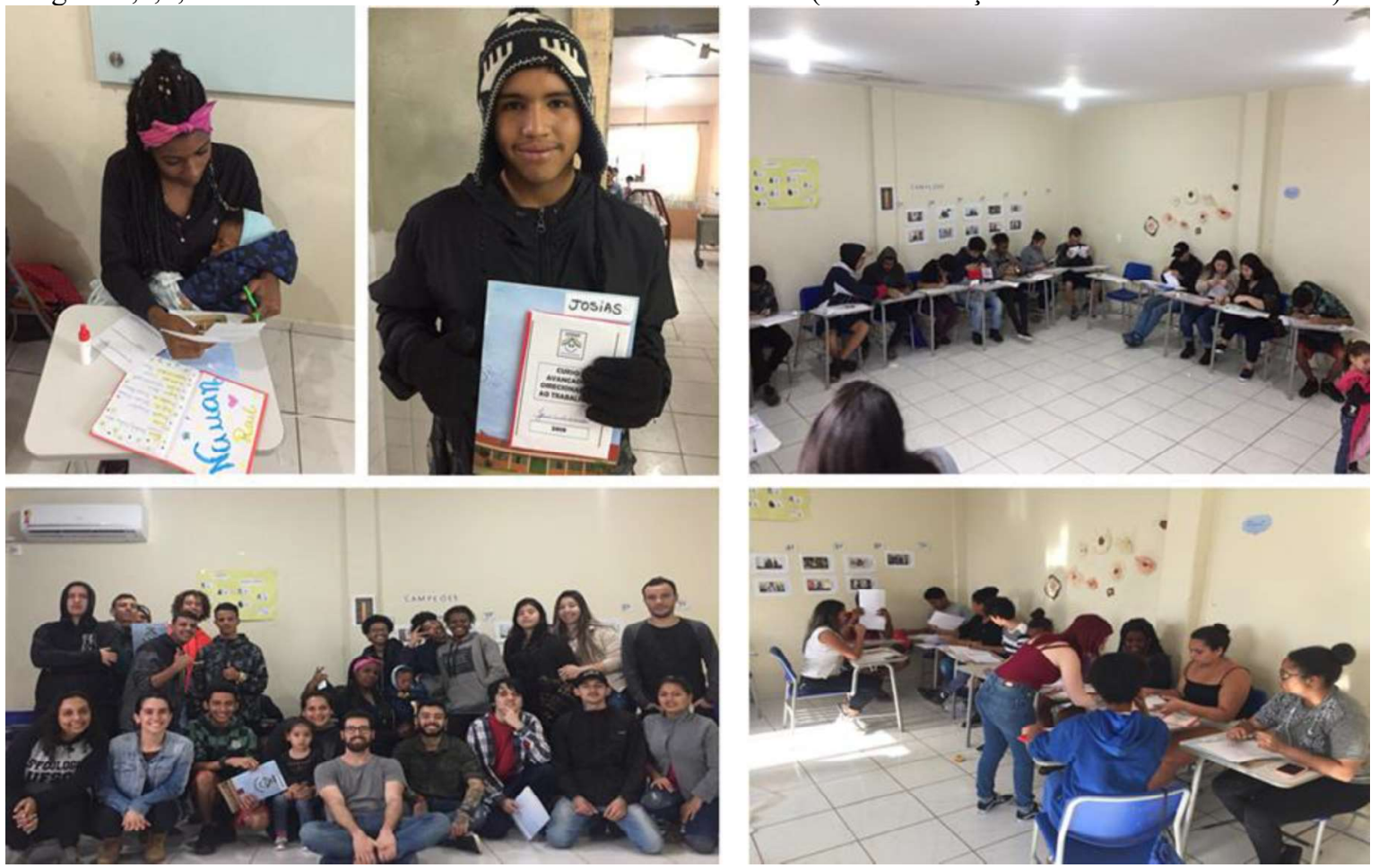

Figura 8 e 9: Curso de oportunidades profissionais de formato remoto em parceria com o CIEE e curso Cidadão Digital em parceria com o Facebook, ambos no formato remoto durante a pandemia do COVID19.
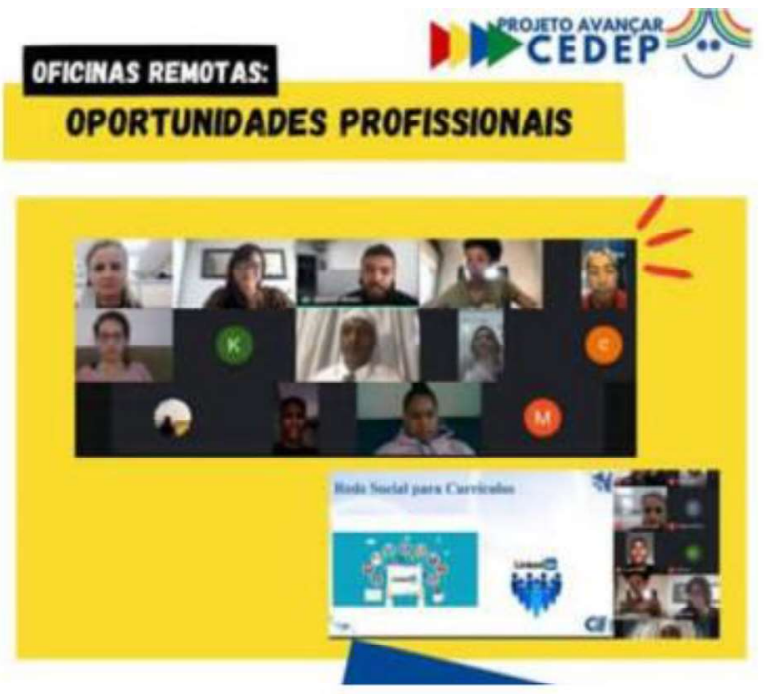

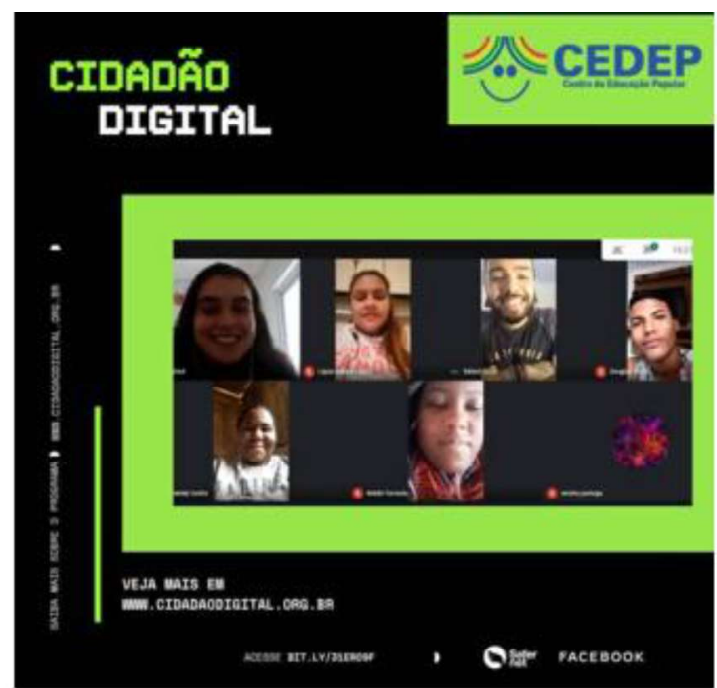


Figura 10: Curso o de designer de sobrancelha

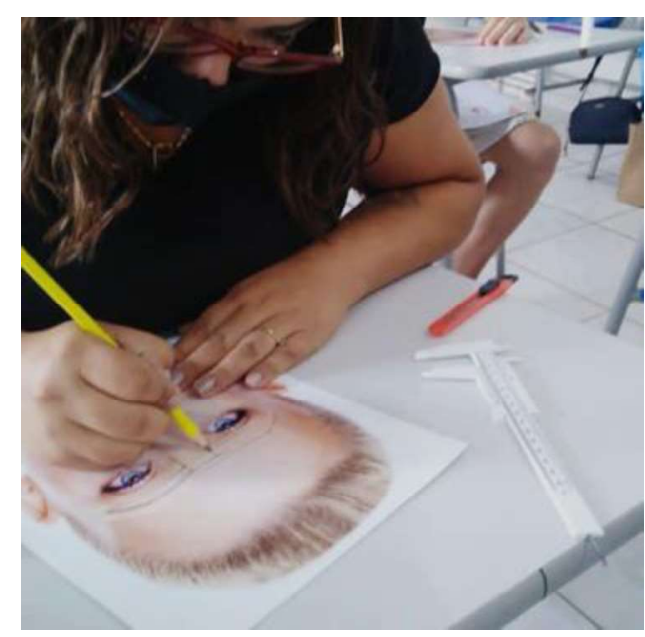

Figura 11 e 12: Curso de assistente administrativo em parceria com o SENAC
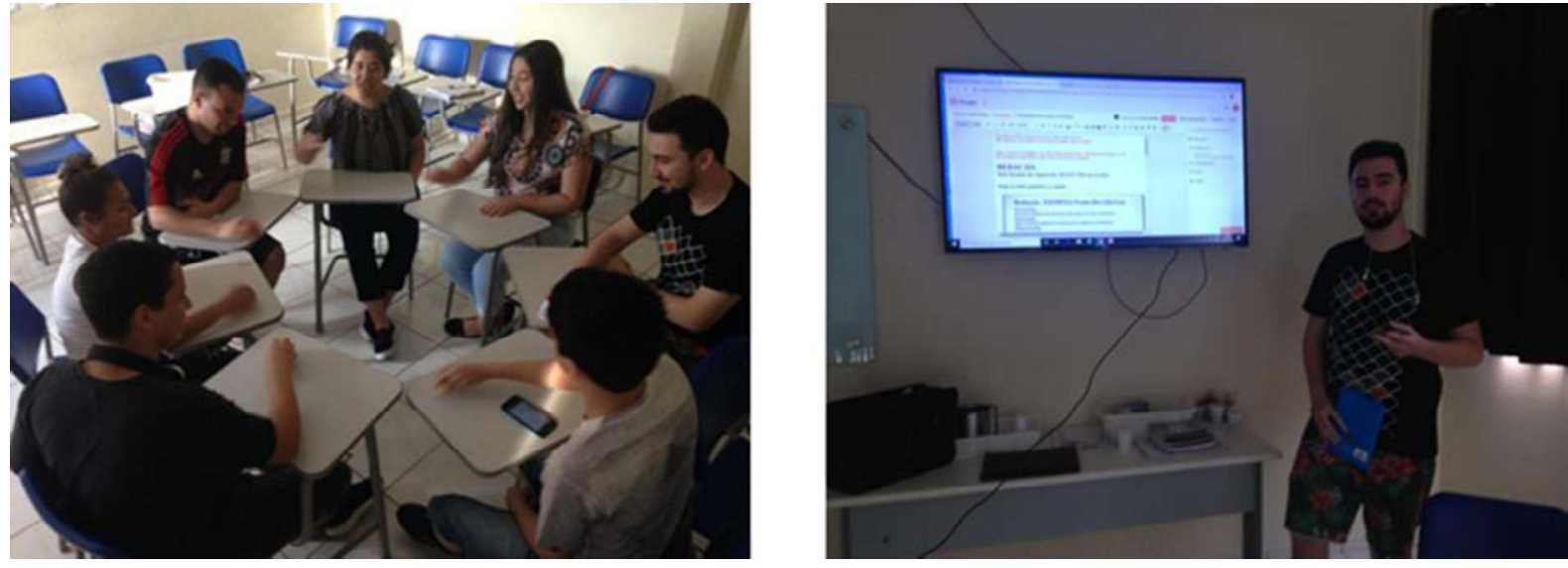

No processo de empreendedorismo contamos com 16 ideias incubadas dentro do processo do projeto Avançar e Cocreation Lab, esses negócios recebem mentorias individuais pelo tempo de 06 meses e estamos em processo de abertura da segunda turma para o segundo semestre de 2021. Foram realizados 06 palestras, 05 Workshops, 06 oficinas temáticas, 06 Eventos e mais de 40 atendimentos individuais, além de assessoria digital, de marketing, jurídica e contábil para todas as ideias de forma integral durante o processo, todas essas ações seguem o modelo do empreendedorismo social, que evidencia a importância da cocriação como forma de potencializar processos inovadores e colaborativos, que trazem como resultado do processo de aprendizagem e construção coletiva, criando redes mais fortes e funcionais. (Alves, 2018) 
Figura 13, 14 e 15: Fotos de atendimentos individuais e personalizados para cada realidade dos participando do Cocreation Lab

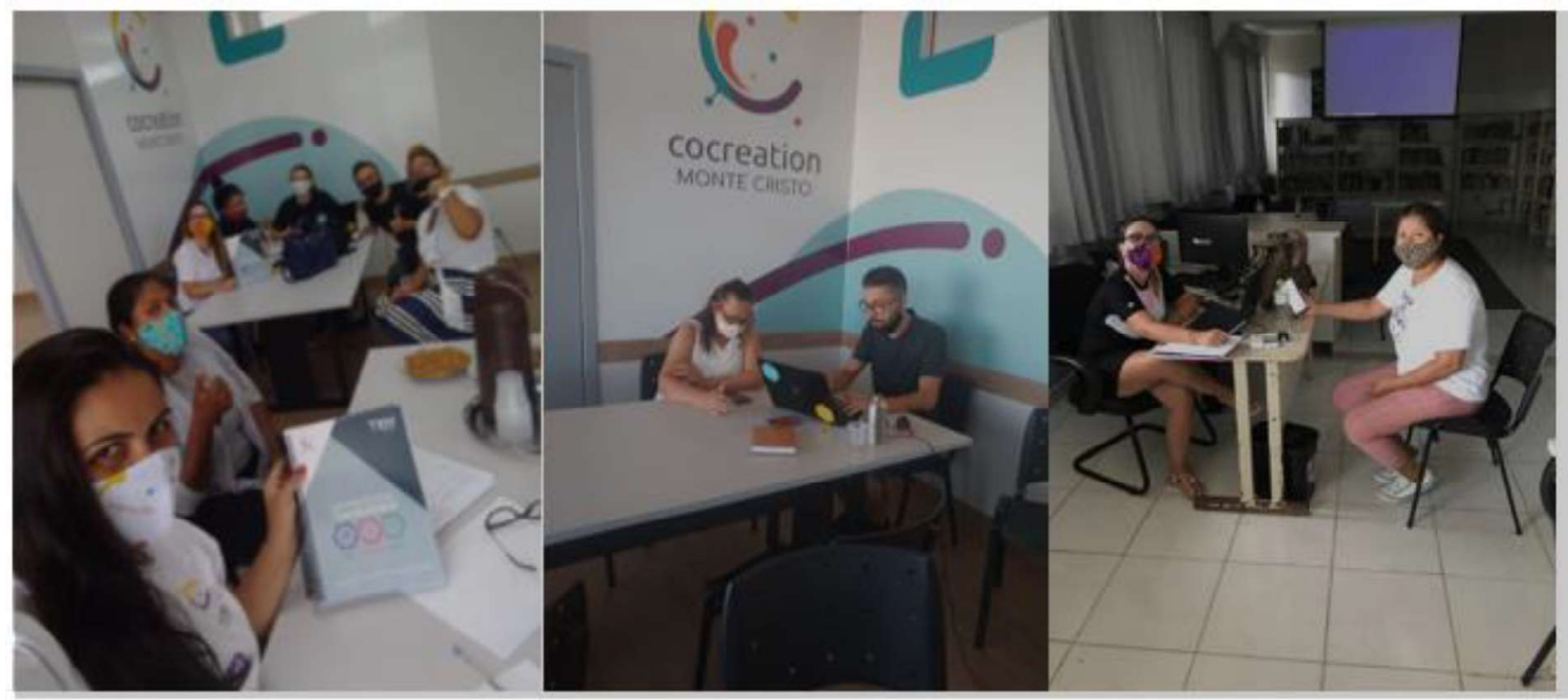

Essas ações culminaram na contratação ou autonomia de nossos educandos, sejam eles jovens ou adultos perante a suas funções laborais, trazendo a eles seu empoderamento social, muitas vezes ceifados pelas faltas de oportunidades geradas por estarem residindo em territórios empobrecidos e marginalizados pelo estado, no último levantamento da turma de jovens formandos de 2020 no CEDEP com idade de 15 anos, dos 29 jovens formados obtivemos um índice de $40 \%$ de contratação dos mesmos em seu primeiro emprego como jovem aprendiz, além disso conseguimos incluir junto aos cursos de formação voltadas ao mercado de trabalho no ano de 2020 mesmo com as dificuldades apresentadas pela pandemia na área de contratação 18 educandos. Isso se deve a formação profissional, resgate da autoestima e senso de pertencimento social e também as largas parcerias que o CEDEP junto ao projeto Avançar vem formando com entidades de Florianópolis. 
Figura 16: Jovens contratados para início de seu primeiro emprego como aprendizes através do projeto Avançar

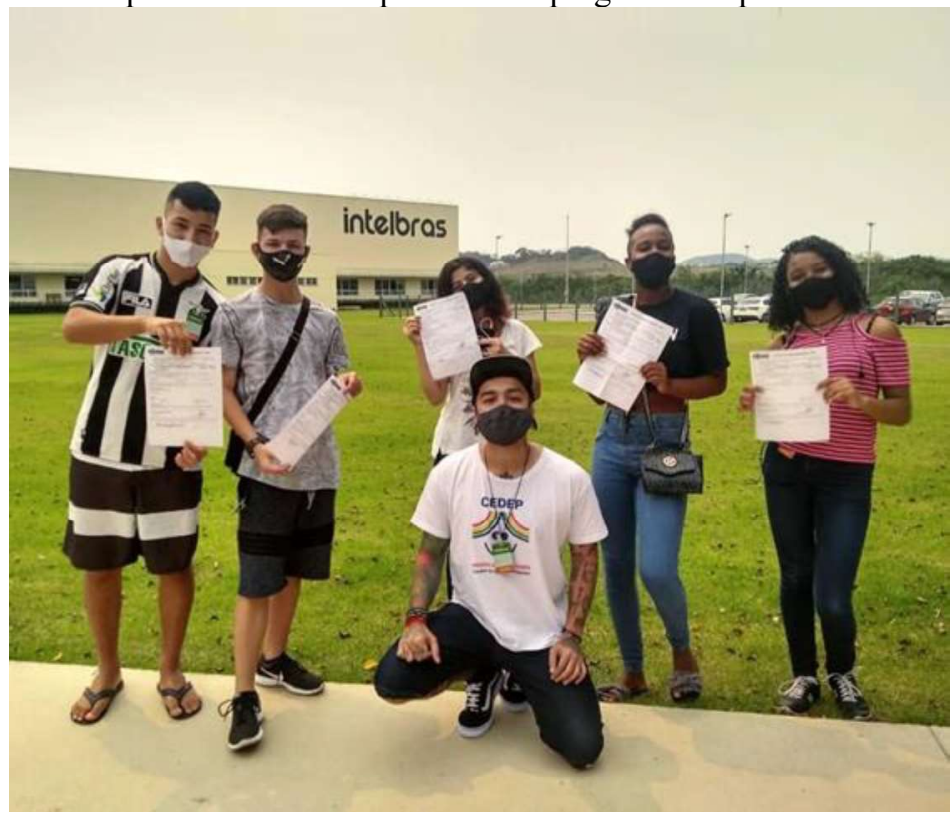

Figura 17: Jovens monitores que trabalham na instituição dentro de formatos educativos e realizam formação em conjunto dos trabalhos

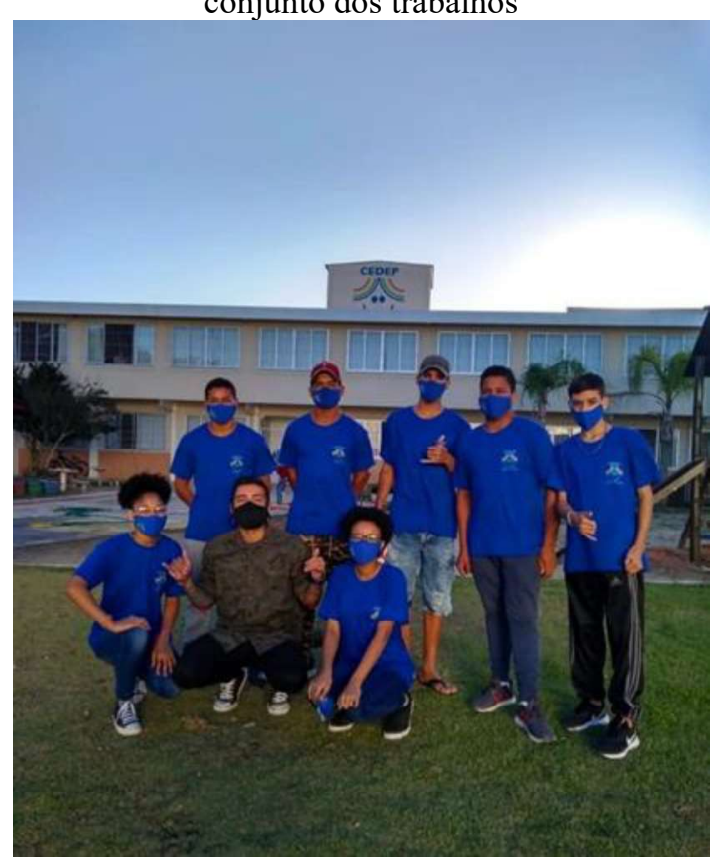

\section{CONCLUSÃO}

Acreditamos que iniciativa como estás vem a trazer diversas oportunidades e auxiliar a este território a ressignificar suas vivências de forma potente a modificar e tomar a frente de seu plano de vida refletindo assim em seu território para maior autonomia e desenvolvimento coletivo, através da iniciativa vemos o engajamento da comunidade nas ações do projeto Avançar e seu crescimento, tanto na procura como também em parceiros, buscando assim estender e aumentar seu atendimento para diferentes níveis educacionais, como o ensino técnico 
e superior como demanda futura, como também abrir mais espaço para agentes da comunidade estarem a frente de tais iniciativas.

\section{REFERÊNCIAS}

ALVES, Juliana da Costa et al. Práticas do processo de cocriação em organizações que inovam abertamente. 2018.

BRASIL, Atlas. Atlas do desenvolvimento humano no Brasil 2013. Acesso em 12/03/2021, v. 22, 2016.

CASALETTI, Solon et al. Perfil epidemiológico dos feridos por arma branca atendidos na emergência do Hospital Florianópolis. 2005.

DE MEDEIROS MORAIS, Jaciária; SOUZA, Ana Paula; COSTA, Temilson. A relação teoria e prática: investigando as compreensões de professores que atuam na educação profissional. Revista Brasileira da Educação Profissional e Tecnológica, v. 1, n. 12, p. 111-124, 2017.

FEFFERMANN, Marisa. O jovem/adolescente "trabalhador" do tráfico de drogas. Cadernos da Defensoria Pública do Estado de São Paulo, p. 137, 2018.

FERREIRA SILVA, Dieici; DA SILVA, Carlos Rodrigues. Inovações tecnológicas: um estudo do processo de produção de carteira de identidade de Paranaiba-MS. Revista Eletrônica Gestão e Serviços, v. 9, n. 2, p. 2413-2431, 2018.

FIGUEIREDO, Natália Gomes da Silva; SALLES, Denise Medeiros Ribeiro. Educação Profissional e evasão escolar em contexto: motivos e reflexões. Ensaio: Avaliação e Políticas Públicas em Educação, v. 25, n. 95, p. 356-392, 2017.

MELLO JÚNIOR, Sérgio Campos de et al. Perfil epidemiológico das vítimas de ferimento por arma de fogo atendidas no hospital Florianópolis. 2004.

MORAES, Gustavo Henrique; DE ALBUQUERQUE, Ana Elizabeth M. As Estatísticas da Educação Profissional e Tecnológica-Silêncios Entre os Números da Formação de Trabalhadores. Textos para discussão, n. 45, p. 54-54, 2019.

RELATÓRIO SINAIS VITAIS - Criança e Adolescente - Direito Deles, Transformação para Todos. disponível em: www.icomfloripa.org.br/wp-content/uploads/2017/05/ Sinais-Vitais2016-Florianópolis-Criança-e-Adolescente-05.17.pdf

SALVI, Naiane Cristina et al. PROCESSO DE PRÉ-INCUBAÇÃO COMO FOMENTO À INOVAÇÃO: O PROGRAMA COCREATION LAB. In: Anais do Congresso Internacional de Conhecimento e Inovação-ciki. 2019.

TURMENA, Leandro; DE AZEVEDO, Mário Luiz Neves. A expansão da Rede Federal de Educação Profissional, Científica e Tecnológica: os institutos federais em questão. Revista Diálogo Educacional, v. 17, n. 54, p. 1067-1084, 2017 